\title{
INFLUENCE OF TISSUE CHANGES IN SUPERFICIAL LAMINA PROPRIA ON PRODUCTION OF CZECH VOWELS
}

\author{
P. Hájek* ${ }^{*}$ P. Švancara**, J. Horáček ${ }^{* * *}$, J. G. Švec ${ }^{\dagger}$
}

\begin{abstract}
Superficial lamina propria (SLP) is a water-like vocal fold (VF) layer located directly under overlying epithelium. Its material properties affect VF motion and thus resulting spectrum of produced sound. Influence of stiffness and damping of the SLP on sound spectrum of Czech vowels is examined using a twodimensional (2D) finite element (FE) model of a human phonation system. The model consists of the VF (structure model) connected with an idealized trachea and vocal tract (VT) (fluid models). Five VTs for all Czech vowels [a:], [e:], [i:], [o:] and [u:] were used and their geometry were based on MRI data. Fluid flow in the trachea and VT was modelled by unsteady viscous compressible Navier-Stokes equations. Such a formulation enabled numerical simulation of a fluid-structure-acoustic interaction (FSAI). Self-sustained oscillations of the VF were described by a momentum equation including large deformations and a homogeneous linear elastic model of material was used. Fluid and structure solvers exchange displacements and boundary forces in each iteration. During closed phase VFs are in contact and fluid flow is separated. We can observe that both the damping and the stiffness of the SLP substantially influence the amplitude and frequency of VFs vibration as well as the open time of the glottis.
\end{abstract}

Keywords: Simulation of phonation, Fluid-structure-acoustic interaction, Czech vowels, Finite element method, Biomechanics of voice.

\section{Introduction}

Changes between convergent and divergent glottal shape play a crucial role in energy transfer during selfsustained oscillations of VFs, see Thomson et al. (2005). Since the structure of VF surface is similar to an inflatable ball filled with water, we can imagine the epithelium as a ball and the SLP as water. Thus tissue changes in the SLP influence self-oscillations of the VFs.

Tanabe et al. (1979) and Chan et al. (2000) measured, modelled and extrapolated damping ratios of selected VF layers, which can be used for FE modelling of VF motion. They showed that VF damping is below a critical damping value with the damping ratio around 0.1. Titze et al. (2017) pointed out that stiffness of the VF is more dominant than tension for oscillation frequencies under $1000 \mathrm{~Hz}$. One of the most recent studies of Zhang (2016) investigated effects of VF thickness of medial surface, glottal opening, subglottal pressure and VF stiffness. He concluded that the increasing stiffness reduces noise and amplifies higherorder harmonics in vowel spectrum to some extent.

The 2D computational model presented in this article continues the previous works of Švancara et al. (2014) and Hájek et al. (2018). The three previous VT shapes for Czech vowels are complemented here by two

* Ing. Petr Hájek: Institute of Solid Mechanics, Mechatronics and Biomechanics, Brno University of Technology; Technická 2896/2; 616 69, Brno; CZ and Department of Biophysics, Palacky University Olomouc; 17. listopadu 12; 771 46, Olomouc; CZ,126528@vutbr.cz

** Ing. Pavel Švancara, Ph.D.: Institute of Solid Mechanics, Mechatronics and Biomechanics; Brno University of Technology; Technická 2896/2; 616 69, Brno; CZ, svancara@fme.vutbr.cz

*** Ing. Jaromír Horáček, DrSc.: Institute of Thermomechanics of the Czech Academy of Sciences; Dolejškova 1402/5; 182 00, Prague; CZ, jaromirh@it.cas.cz

$\dagger \quad$ RNDr. Jan G. Švec, Ph.D.: Department of Biophysics, Palacky University Olomouc; 17. listopadu 12; 771 46, Olomouc; CZ, jan.svec@upol.cz 
additional VTs for Czech vowels [e:] and [o:] reconstructed from MRI data, see Radolf (2010). Also, the fluid FE mesh was refined here to capture smaller eddies.

\section{Methods}

All 2D FE models of FSAI during VF self-oscillation were developed in the software ANSYS 15.0, see Fig. 1 a)-e),g). The models consist of simplified trachea, four-layered VF based on M5 geometry, see Scherer et al. (2001), and five VTs for all Czech vowels [a:], [e:], [i:], [o:] and [u:]. All the models are composed of 16097 linear elements with 16306 nodes. Material parameters (including damping) are summarized in Fig. 1 f), i).

The computational algorithm is as follows: the model is excited by a mean lung pressure $p_{L u}=270 \mathrm{~Pa}$ at the entrance to the trachea (Fig. 1 a)). The air flow propagates through the trachea and loads the VFs which start to move. When VFs open the air flows through the VT and generates pressure waves forming the vowel spectrum. Deformation of the fluid mesh is solved by an in-house Arbitrary-Lagrangian-Eulerian algorithm, details in Švancara et al. (2014).

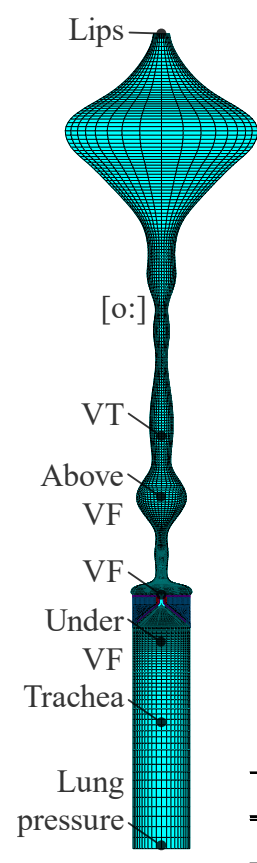

a)

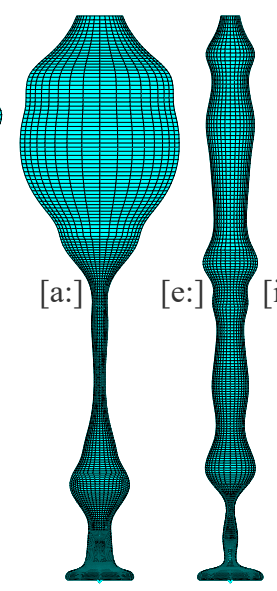

b)

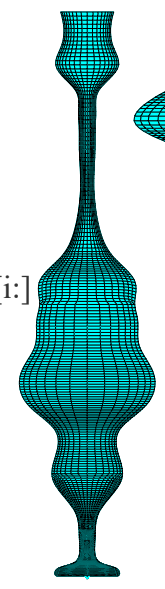

d)

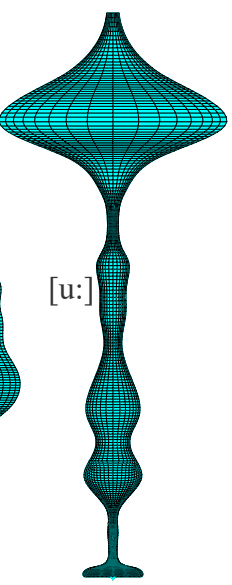

e)

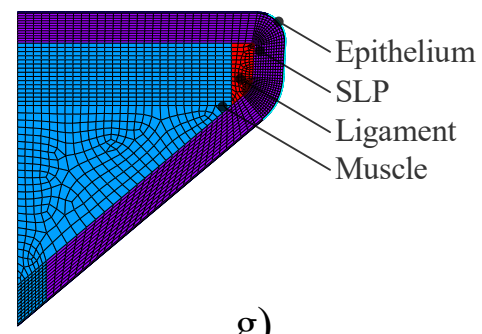

g)

\begin{tabular}{ccc}
\hline VARIANT & $\mathrm{b}_{\mathrm{p} 1}[-]$ & $\mathrm{b}_{\mathrm{p} 2}[-]$ \\
\hline \hline 1 & 0.05 & 0.10 \\
\hline 2 & 0.10 & 0.20 \\
\hline 3 & 0.20 & 0.30 \\
\hline 4 & 0.30 & 0.40 \\
\hline
\end{tabular}

h)

\begin{tabular}{cccc}
\hline STRUCTURE & $\mathrm{E}[\mathrm{Pa}]$ & $\mu[-]$ & $\rho\left[\mathrm{kg} \cdot \mathrm{m}^{-3}\right]$ \\
\hline \hline Epithelium & 25000 & 0.49 & 1040 \\
\hline SLP & $2000 \div 3500$ & 0.49 & 1040 \\
\hline Ligament & 8000 & 0.49 & 1040 \\
\hline Muscle & 65000 & 0.40 & 1040 \\
\hline
\end{tabular}

i)

Fig. 1: a) 2D FE model for the [o:] vowel, $b$ )-e) vocal tracts for the remaining vowels, $f$ ) material properties of the fluid model where cair - speed of sound in the air, $\eta$ - dynamic viscosity and $\rho$-density, $g$ ) fourlayered model of $V F, h$ ) four variants of chosen damping ratios and i) material properties of the VF where $\mathrm{E}-$ Young's modulus, $\mu$-Poisson's ratio and $\rho$-density.

Eighty combinations of tested parameters were prepared, see Tab. 1. Four variants of Young's moduli of the SLP ( $\left.\mathrm{E}_{\mathrm{SLP}}\right)$ were used for each vowel and four variants of damping were used for each stiffness $\mathrm{E}_{\mathrm{SLP}}$ according to Tab. 1. From pairs of damping ratios $b_{p 1}$ and $b_{p 2}($ Fig. $1 \mathrm{~h})$ ) and from the natural frequencies of the VF coefficients of proportional damping $\alpha$ and $\beta$ were calculated and used in computations, for details see Hájek et al. (2018). Each computation of a $0.1 \mathrm{~s}$ long phonation took between 7 and 12 hours on Intel® Core ${ }^{\mathrm{TM}} \mathrm{i} 7-7700 \mathrm{~K}$ with $32 \mathrm{~Gb}$ of RAM.

\section{Results and discussion}

The structural results are given in Tab. 1. Vibration frequency $f$, maximal width of glottis $W G_{\max }$ and open quotient $O Q$ were evaluated from one of the last computed periods, see Fig. 2 (top left). From the results it is apparent that both the increasing stiffness and increasing damping reduce $W G_{\max }$. Rising stiffness also 
decreases $O Q$ whereas damping has an opposite influence in some variants. Frequency of self-sustained VF vibrations $f$ lies between 80 and $170 \mathrm{~Hz}$ which is in a range of normal male phonation.

Tab. 1: Vibration characteristics of VFs.

\begin{tabular}{|c|c|c|c|c|c|c|c|c|c|c|c|c|c|c|c|c|c|}
\hline \multirow{2}{*}{$\begin{array}{l}E_{S L P} \\
{[\mathrm{~Pa}]}\end{array}$} & \multirow{2}{*}{$\alpha\left[\mathrm{s}^{-1}\right]$} & \multirow{2}{*}{$\beta[\mathrm{s}]$} & \multicolumn{4}{|c|}{ [a:] } & \multicolumn{3}{|l|}{ [e:] } & \multicolumn{2}{|l|}{ [i:] } & \multicolumn{3}{|c|}{ [o:] } & \multicolumn{3}{|c|}{ [u:] } \\
\hline & & & $f[\mathrm{~Hz}]$ & $\begin{array}{c}W G_{\max } \\
{[\mathrm{mm}]}\end{array}$ & $O Q[-]$ & $f[\mathrm{~Hz}]$ & $\begin{array}{r}W G_{\max } \\
{[\mathrm{mm}]}\end{array}$ & $O Q[-]$ & $f[\mathrm{~Hz}]$ & $\begin{array}{c}W G_{\max } \\
{[\mathrm{mm}]} \\
\end{array}$ & $O Q[-]$ & $f[\mathrm{~Hz}]$ & $\begin{array}{c}W G_{\max } \\
{[\mathrm{mm}]}\end{array}$ & $O Q[-]$ & $f[\mathrm{~Hz}]$ & $\begin{array}{c}W G_{\max } \\
{[\mathrm{mm}]}\end{array}$ & $O Q[-]$ \\
\hline \multirow{4}{*}{2000} & 0.5083 & 0.0002 & \multicolumn{3}{|c|}{ Computation crashed } & \multicolumn{3}{|c|}{ Computation crashed } & \multicolumn{3}{|c|}{ Computation crashed } & \multirow{2}{*}{\multicolumn{3}{|c|}{ Computation crashed }} & \multirow{2}{*}{\multicolumn{3}{|c|}{ Computation crashed }} \\
\hline & 1.0165 & 0.0004 & 130 & 0.39 & 0.26 & 137 & 0.48 & 0.37 & 141 & 0.45 & 0.38 & & & & & & \\
\hline & 60.3776 & 0.0006 & 130 & 0.39 & 0.30 & 137 & 0.49 & 0.41 & 137 & 0.43 & 0.42 & 135 & 0.46 & 0.32 & 137 & 0.42 & 0.33 \\
\hline & 119.7386 & 0.0007 & 132 & 0.37 & 0.33 & 143 & 0.46 & 0.43 & 133 & 0.43 & 0.44 & 133 & 0.44 & 0.33 & 133 & 0.41 & 0.35 \\
\hline \multirow{4}{*}{2500} & 1.7917 & 0.0002 & 130 & 0.34 & 0.22 & \multicolumn{3}{|c|}{ Computation crashed } & 154 & 0.38 & 0.28 & 139 & 0.36 & 0.22 & \multicolumn{3}{|c|}{ Computation crashed } \\
\hline & 3.5834 & 0.0004 & 115 & 0.32 & 0.24 & 143 & 0.42 & 0.36 & 137 & 0.38 & 0.38 & 132 & 0.37 & 0.28 & 130 & 0.34 & 0.30 \\
\hline & 64.4495 & 0.0006 & 116 & 0.30 & 0.27 & 133 & 0.39 & 0.39 & 133 & 0.36 & 0.41 & 128 & 0.34 & 0.31 & 130 & 0.34 & 0.32 \\
\hline & 125.3155 & 0.0007 & 120 & 0.30 & 0.29 & 135 & 0.39 & 0.39 & 115 & 0.42 & 0.32 & 123 & 0.32 & 0.32 & 125 & 0.32 & 0.34 \\
\hline \multirow{4}{*}{3000} & 2.7622 & 0.0002 & 119 & 0.29 & 0.20 & 169 & 0.32 & 0.31 & 137 & 0.33 & 0.30 & 116 & 0.28 & 0.19 & 112 & 0.31 & 0.20 \\
\hline & 5.5243 & 0.0004 & 128 & 0.29 & 0.24 & 133 & 0.33 & 0.28 & 169 & 0.27 & 0.29 & 130 & 0.29 & 0.25 & 108 & 0.30 & 0.23 \\
\hline & 67.5990 & 0.0006 & 103 & 0.27 & 0.23 & 116 & 0.29 & 0.28 & 106 & 0.27 & 0.24 & 111 & 0.28 & 0.26 & 104 & 0.28 & 0.25 \\
\hline & 129.6737 & 0.0007 & 99 & 0.26 & 0.23 & 118 & 0.29 & 0.28 & 112 & 0.25 & 0.27 & 100 & 0.28 & 0.23 & 122 & 0.27 & 0.29 \\
\hline \multirow{3}{*}{3500} & 3.5315 & 0.0002 & 108 & 0.23 & 0.17 & 119 & 0.26 & 0.18 & 100 & 0.21 & 0.14 & 133 & 0.25 & 0.21 & 116 & 0.24 & 0.20 \\
\hline & 7.0631 & 0.0004 & 85 & 0.24 & 0.16 & 122 & 0.25 & 0.26 & 78 & 0.24 & 0.16 & 106 & 0.26 & 0.21 & 104 & 0.25 & 0.21 \\
\hline & $\begin{array}{r}70.1592 \\
133.2553\end{array}$ & $\begin{array}{l}0.0005 \\
0.0007\end{array}$ & \multicolumn{3}{|c|}{ VF did not open } & \multicolumn{3}{|c|}{ VF did not open } & \multicolumn{3}{|c|}{ VF did not open } & \multicolumn{3}{|c|}{ VF did not open } & \multicolumn{3}{|c|}{ VF did not open } \\
\hline
\end{tabular}

Fig. 2 on the right shows the acoustic pressure measured $5 \mathrm{~mm}$ below lips from which point the power spectral densities are evaluated. Peaks of flow velocity between VFs occur around the start and end of open phase which we can see in the Fig. 2 (bottom left).
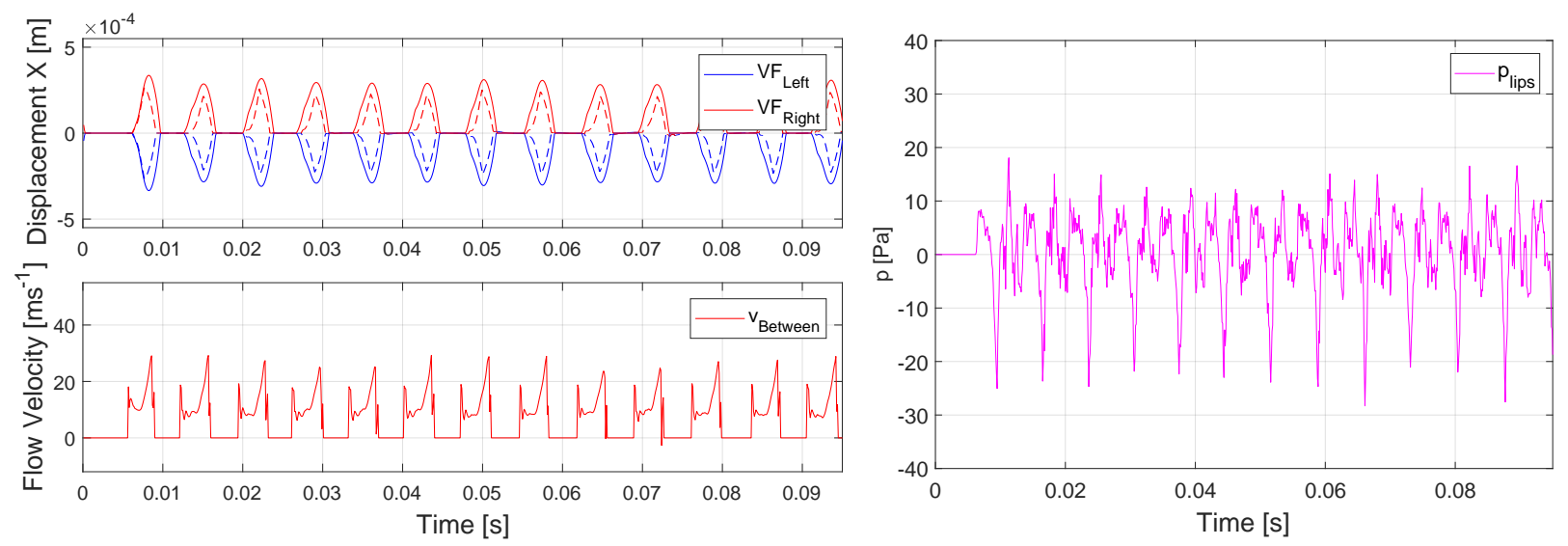

Fig. 2: Example of results for vowel [e:], most damped case with $\mathrm{E}_{\mathrm{SLP}}=2000 \mathrm{~Pa}$. Top left: displacement of VFs in mediolateral direction from a node on the left and right VF medial surface (solid line) and from minimal glottal width (dashed line). Bottom left: flow velocity from a node between VFs. Right: acoustic pressure near the lips.

Fig. 3 shows comparison between two spectra of acoustic pressure near the lips for the vowel [o:]. One can observe that the less stiff and more damped SLP (left graph) can generate harmonic peaks near the first and second formant frequency while all the spectral peaks generated by stiffer and less damped SLP (right graph) are lower and flattened. The first two formants lie close together at $550 \mathrm{~Hz}$ and $700 \mathrm{~Hz}$. These two formats are in the range measured by Merhaut (1972). Frequency shift was not observed among computed variants.

\section{Conclusion}

Extensive sensitivity analysis was done to explore the influence of stiffness and damping of SLP on VFs motion and produced sound for all Czech vowels. The developed 2D FE model of a human phonation 

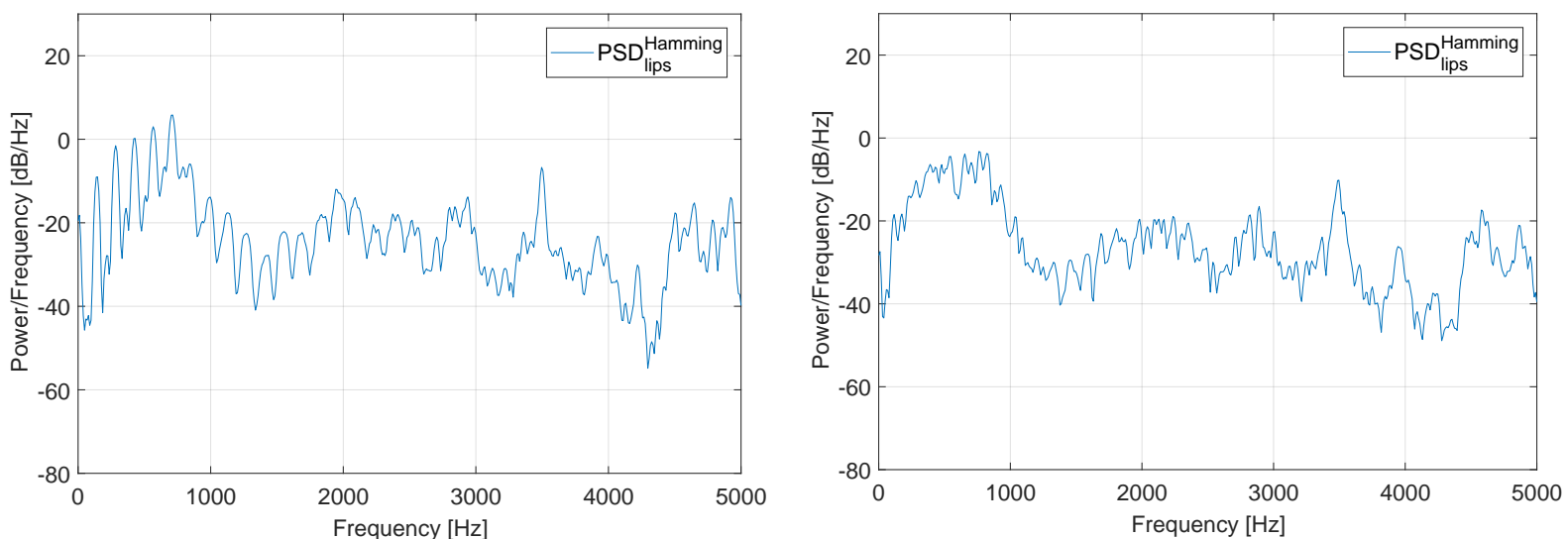

Fig. 3: Power spectral densities of acoustic pressure at node near the lips for vowel [o:]. Left: $\mathrm{E}_{\mathrm{SLP}}=2000 \mathrm{~Pa}$ with damping var. 3 according Fig. 1 h). Right $\mathrm{E}_{\mathrm{SLP}}=3500 \mathrm{~Pa}$ with damping var. 1 .

enables to use different shapes of VTs and allows changing various model parameters such as stiffness and damping. Results show that varying properties of SLP affect motion of VFs and resulting vibration characteristics. Maximum width of glottis is most affected by these properties. Properties of SLP tissue could vary due to pathology, for instance Reinke's edema.

\section{Acknowledgement}

This work was supported by Czech Science Foundation project no. 19-04477S "Modelling and measurements of fluid-structure-acoustic interactions in biomechanics of human voice production". Access to computing and storage facilities owned by parties and projects contributing to the National Grid Infrastructure MetaCentrum provided under the programme "Projects of Large Research, Development, and Innovations Infrastructures" (CESNET LM2015042), is greatly appreciated.

\section{References}

Chan, R. W., Titze, I. R. (2000) Viscoelastic shear properties of human vocal fold mucosa: theoretical characterization based on constitutive modeling. The Journal of the Acoustical Society of America, 107, 1, pp 565-580, ISSN 00014966 doi: $10.1121 / 1.428354$

Hájek, P., Švancara, P., Horáček, J., Švec, J. G. (2018) On the FE Modelling of Vocal Folds Pathologies. In: Computational Mechanics 2018: Book of extended abstracts, Plzeň, University of West Bohemia.

Merhaut, J. (1972) Fundamentals of physiological acoustics and theory of natural acoustic signals (in Czech). Prague, Czech Technical University.

Radolf, V. (2010) Direct and inverse task in acoustics of the human vocal tract. PhD Thesis, Czech Technical University in Prague.

Scherer, R. C., Shinwari, D., De Wit, K. J., Zhang, C., Kucinschi, B. R., \& Afjeh, A. A. (2001) Intraglottal pressure profiles for a symmetric and oblique glottis with a divergence angle of 10 degrees. Journal of the Acoustical Society of America, 109, 4, pp 1616-1630.

Švancara, P., Horáček, J., Martínek, T., Švec, J. G. (2014) Numerical simulation of videokymographic images from the results of the finite element model. In: Engineering Mechanics 2014, Svratka, pp 640-643.

Tanabe, M., Igghiki, N., Sawada, M. (1979) Damping Ratio of the Vocal Cord. Folia Phoniatrica et Logopaedica, 1979, 31, pp 27-34.

Thomson, S. L., Mongeau, L., Frankel, S. H. (2005) Aerodynamic transfer of energy to the vocal folds. Journal of the Acoustical Society of America, 118, 3, pp 1689-1700, do i:10.1121/1.2000787.

Titze, I. R., Alipour, F., Blake, D., Palaparthi, A. (2017) Comparison of a fiber-gel finite element model of vocal fold vibration to a transversely isotropic stiffness model. The Journal of the Acoustical Society of America, 142, 3, pp 1376-1383, ISSN 0001-4966, doi:10.1121/1.5001055.

Zhang, Z. (2016) Cause-effect relationship between vocal fold physiology and voice production in a three-dimensional phonation model. The Journal of the Acoustical Society of America, 139, 4, pp 1493-1507, ISSN 0001-4966, doi:10.1121/1.4944754. 